\title{
Mortality and Outcome of Severe Traumatic Brain Injury in a Swiss Level One Trauma Center
}

Michael Kuenzler, Christian Tasso Braun and Monika Brodmann Maeder

Department of Emergency Medicine, Inselspital, Bern University Hospital, CH-3010 Bern, Switzerland

*Corresponding author: Monika Brodmann Maeder, Department of Emergency Medicine, Inselspital, Bern University Hospital, CH-3010 Bern, Switzerland, Tel: +41 31 63280 54; Fax: +4131632 03 71; E-mail: monika.brodmann@insel.ch

Received date: September 27, 2014, Accepted date: November 04, 2014, Published date: November 11, 2014

Copyright: ( 2015 Kuenzler M, et al. This is an open-access article distributed under the terms of the Creative Commons Attribution License, which permits unrestricted use, distribution, and reproduction in any medium, provided the original author and source are credited.

\begin{abstract}
The present report describes the demography and outcome of severe traumatic brain injury (TBI) in, Bern University Hospital, a Swiss level one trauma center. The primary outcome was death after one year; the secondary outcome was patient status two weeks post-injury.

The included study patients were aged $\geq 16$ with severe TBI, admitted to the tertiary trauma center with an intracranial lesion AIS $\geq 4$ based on Computer Tomography (CT) findings. 178 patients, predominantly males (75.8\%), with a mean age of $54 \pm 23.3$ years, were included. The main causes of the accidents were falls $(52.6 \%)$, followed by road traffic accidents (RTA, 35.8\%). The mean injury severity score (ISS) was $28.5 \pm 13$; the mean GCS at the site of the accident was $10 \pm 4.4 .35 .4 \%$ of the patients underwent neurosurgical intervention. The mean Glasgow Coma scale (GCS) at day 14 was $13.8 \pm 2.6 .47(26.4 \%)$ patients died, $39(82.9 \%)$ of them within the first 14 days.

The characteristics and outcome of patients with severe TBI at Bern university hospital were similar to those found in other centers in industrialized countries. In general, mortality was highest in the first few days, and the surviving patients had a favorable neurological outcome. Younger patients were more likely to die in the first days post-injury, and the survivors had a good neurological outcome. Patients aged over 60 were more likely to have less severe TBI and predominantly died later.
\end{abstract}

Keywords: Severe traumatic brain injury; Prevalence; Mechanism; Mortality; Elderly

\section{Introduction}

A recent nationwide, epidemiological study investigated the incidence and outcome of severe traumatic brain injury (TBI) in Switzerland [1]. In their publication, they reported an incidence of 10.58 per 100,000 adult populations per year, with a difference between patients $<60$ years and those 60 years and above ( 7.9 vs. 22.4 per 100,000/year, respectively). The median age was 55 years and the age distribution showed two peaks - at 20-30 years and 60-70 years. The main accident mechanisms in elderly patients were falls and in younger patients road traffic accidents (RTA). The median GCS at the site of the accident was 9, and the majority of patients had an Abbreviated Injury Severity score (AIS)[2] of the head of 4 or 5 and a median Injury Severity Score (ISS) of 25 . The 14-day mortality was $30.2 \%$ and most patients died within the first days after the accident. The present study aimed to investigate the outcome and demography of severe TBI at Bern University Hospital, a Swiss level one trauma center, which covers rural, mountainous and urban areas. The primary outcome was death after one year follow-up. Secondary outcomes were patient status two weeks post-injury, which included the neurological condition as measured with the Glasgow Coma Scale (GCS), site of treatment, length of hospital stay and whether the patient was transferred to a neurorehabilitation unit.

\section{Material and Methods}

\section{Study population}

For this study, patients of the emergency department of the university hospital in Bern were included from March first 2009 to April 30, 2010. New admissions to the Emergency Department were screened for eligible patients on a daily basis. Patients who met the following criteria were eligible for inclusion: Patients admitted to Bern University Hospital aged $\geq 16$ with severe TBI due to blunt or penetrating trauma, with intracranial lesions classified $\geq 4$ according to the 2005 revision of the Abbreviated Injury Severity Score (Head AIS) $[2,3]$. The local study coordinator decided on the inclusion criteria of the patient on the basis of the computed tomography (CT) findings within the first $24 \mathrm{~h}$ of admission,

Local IRB approval was obtained, and informed consent was given after inclusion, either by the patients or their relatives. When the patients were neurologically capable of giving informed consent, they were asked directly. If the patients were not neurologically capable of giving informed consent themselves, their relatives were contacted and asked for consent.

\section{Patient data}

Collected patient data included forms for patient demographics, documents from pre hospital emergency services and from the emergency department and the outcome at day 14. If the patient was transferred from a regional hospital, two additional forms were used, 
Citation: Kuenzler M, Braun CT, Maeder MB (2015) Mortality and Outcome of Severe Traumatic Brain Injury in a Swiss Level One Trauma

Page 2 of 6

for the first emergency department and inter hospital transfer. The data collection forms were based on the Utstein-style documentation for major trauma [4]. Beside head trauma, all additional injuries were recorded and coded according to the AIS system [2]. The Injury Severity Score (ISS) was calculated from the AIS Score for each body region [5].

\section{Outcome}

The patients were followed up for one year post-injury for possible death. Patient outcome was evaluated 14 days post-injury. The outcome measurements included the Glasgow Coma Scale, death before day 14, place of current treatment and transfer to a rehabilitation unit.

\section{Mechanism of injury}

The injury mechanisms were split into four main categories, according to the description of the emergency services form: Road traffic accident (RTA), falls, sports accidents and other (includes penetrating trauma and train accidents). The RTAs were subdivided by the method of transport.

\section{Statistical Analysis}

Descriptive statistical analysis was performed with SPSS 22. For the one-year outcome, the survival curve was calculated using KaplanMeier's method. Subgroups were built for demographical analysis. The subgroups were compared with ANOVA post-hoc tests and Pearson's chi-square test, where appropriate. The level of significance for differences in the subgroups was defined as $\mathrm{p}<0.05$.

\section{Results}

\section{Patient data}

Of the approx. 30,000 patients treated at the University Emergency Department during the study period, 178 were included in the study in accordance with the inclusion criteria. 91 patients could be followed up to one year post-injury. Mean age at the time of the accident was $54.1 \pm 23.3$ years. $75.8 \%(\mathrm{~N}=135)$ were men and $24.2 \%$ female $(\mathrm{nN}=$ 43). The age distribution showed two peaks: one in the group $<30$ years and a higher peak in the group $>60$ years (Table 1 ).

\begin{tabular}{|c|c|c|c|c|c|c|c|c|c|c|c|c|c|}
\hline \multicolumn{13}{|l|}{ Age category } & \multirow{3}{*}{$\begin{array}{l}p \\
\text { value }\end{array}$} \\
\hline & \multicolumn{2}{|c|}{$\begin{array}{l}\text { All } \\
\mathrm{N}(\%)\end{array}$} & \multicolumn{2}{|c|}{$\begin{array}{l}<30 \\
N(\%)\end{array}$} & \multicolumn{2}{|c|}{$\begin{array}{l}30-45 \\
N(\%)\end{array}$} & \multicolumn{2}{|c|}{$\begin{array}{l}45-60 \\
N(\%)\end{array}$} & \multicolumn{2}{|c|}{$\begin{array}{l}60-75 \\
N(\%)\end{array}$} & \multicolumn{2}{|c|}{$\begin{array}{l}>75 \\
\mathrm{~N}(\%)\end{array}$} & \\
\hline Age & 54.1 & \pm 23.3 & 20.4 & \pm 3.3 & 34.6 & \pm 4.8 & 54.6 & \pm 5.0 & 67.0 & \pm 4.6 & 82.0 & \pm 5.1 & \\
\hline \multicolumn{14}{|l|}{ Gender } \\
\hline Male & 135 & (75.8) & 31 & $(75.6)$ & 16 & $(76.2)$ & 28 & $(90.3)$ & 36 & (80) & 24 & (60) & 0.051 \\
\hline Female & 43 & $(24.2)$ & 10 & $(24.4)$ & 5 & $(23.8)$ & 3 & $(9.7)$ & 9 & (20) & 16 & (40) & \\
\hline \multicolumn{14}{|l|}{ Accident mechanism } \\
\hline Sport & 10 & $(5.8)$ & 2 & (5.3) & 2 & (10) & 3 & (9.7) & 2 & (4.5) & 1 & (2.5) & \\
\hline Fall & 91 & $(52.6)$ & 7 & $(18.4)$ & 10 & (50) & 14 & $(45.2)$ & 33 & (75) & 27 & (67.5) & \\
\hline Other & 10 & (5.8) & 4 & (10.5) & 3 & (15) & 1 & (3.2) & 1 & (2.3) & 1 & (2.5) & \\
\hline RTA & 62 & (35.8) & 25 & $(65.8)$ & 5 & (25) & 13 & (41.9) & 8 & (18.2) & 11 & (27.5) & \\
\hline \multicolumn{14}{|l|}{ Neurosurgical Intervention } \\
\hline Decompressive craniotomy & 22 & (12.4) & 6 & (14.6) & 3 & (14.3) & 3 & $(9.7)$ & 6 & (13.3) & 4 & (10) & \\
\hline Hematoma evacuation & 10 & (5.6) & 2 & (4.9) & 3 & (14.3) & 2 & (6.5) & 3 & (6.7) & 0 & & \\
\hline Intraventricular drainage & 19 & (10.7) & 4 & (9.8) & 1 & $(4.8)$ & 2 & (6.5) & 10 & (22.2) & 2 & (5) & \\
\hline Other & 12 & (6.7) & 6 & (14.6) & 0 & & 1 & (3.2) & 5 & (11.1) & 0 & & \\
\hline None & 115 & $(64.6)$ & 23 & $(56.1)$ & 14 & $(66.7)$ & 23 & $(74.2)$ & 21 & $(46.7)$ & 34 & (85) & \\
\hline Indirect admission & 54 & $(30.3)$ & 9 & (22) & 4 & (19) & 9 & (29) & 15 & (33.3) & 17 & (42.5) & 0.23 \\
\hline \multicolumn{14}{|l|}{ Place of treatment at day 14} \\
\hline Trauma Center & 21 & $(11.8)$ & 8 & (19.5) & 4 & (19) & 2 & (6.5) & 5 & (11.1) & 2 & (5) & \\
\hline External Hospital & 80 & $(44.9)$ & 9 & (22) & 10 & $(47.6)$ & 14 & $(45.2)$ & 25 & $(55.6)$ & 22 & (55) & \\
\hline
\end{tabular}




\begin{tabular}{|c|c|c|c|c|c|c|c|c|c|c|c|c|c|}
\hline Deceased & 38 & $(21.3)$ & 8 & $(19.5)$ & 3 & $(14.3)$ & 3 & $(9.7)$ & 10 & $(22.2)$ & 14 & (35) & \\
\hline Home & 11 & $(6.2)$ & 7 & $(17.1)$ & 0 & (0) & 2 & $(6.5)$ & 1 & $(2.2)$ & 1 & $(2.5)$ & \\
\hline Neurorehabilitation & 28 & $(15.7)$ & 9 & (22) & 4 & (19) & 10 & $(32.3)$ & 4 & $(8.9)$ & 1 & $(2.5)$ & \\
\hline Mean time of hospitalization & 11.6 & \pm 12.7 & 10.0 & \pm 10.0 & 10.2 & \pm 10.9 & 11.5 & \pm 15.1 & 15.2 & \pm 14.9 & 10.5 & \pm 11.4 & 0.34 \\
\hline \multicolumn{14}{|l|}{ Death } \\
\hline Overall death & 47 & $(26.4)$ & 8 & (19.5) & 3 & $(14.3)$ & 3 & $(9.7)$ & 15 & $(33.3)$ & 18 & (45) & 0.004 \\
\hline Mean survival & 32.8 & \pm 86.4 & 0.6 & \pm 0.48 & 0.25 & \pm 0.33 & 1.7 & \pm 1.5 & 42.5 & \pm 91.5 & 49.6 & \pm 109.8 & \\
\hline \multicolumn{14}{|l|}{ Neurorehabilitation } \\
\hline Patients in rehabilitation & 58 & $(32.6)$ & 15 & $(36.6)$ & 5 & $(23.8)$ & 9 & (29.9) & 19 & $(42.2)$ & 10 & (25) & 0.38 \\
\hline Duration of rehabilitation & 74.9 & \pm 77.2 & 74.3 & \pm 71.8 & 60.0 & \pm 32.9 & 91.9 & \pm 87.5 & 93.1 & \pm 99.7 & 35.3 & \pm 24.1 & 0.43 \\
\hline
\end{tabular}

Table 1: Descriptive Data of the Patients. The patient population was subdivided into age groups and overall means were calculated. Percentage values indicate the percentage in the subgroup

\section{Mechanism of injury}

Falls were the main cause of severe TBI in $52.6 \%$ of patients $\mathrm{N}=$ 91), followed by road traffic accidents (RTA) in $35.8 \%$ of patients $(\mathrm{N}=$ 62). Minor causes were sports and other accidents - each with $5.8 \%(\mathrm{~N}$ $=10$ ). Other accidents included train accidents, gunshots and injuries through other objects. As indicated in Fig. 1 and Table 1, the subgroups differed in the cause of the accidents. In patients $<30$ years, the main cause of the accidents were RTAs (65.8\%). The percentage diminishes with the increasing age, but exhibited another peak in the age group of $45-60$ years $(41.9 \%)$. Conversely, the rate of falls increased with age, from $18.4 \%$ in the $<30$ age group to the peak percentage in the 60 - 75 years group (75\%) (Figure 1).

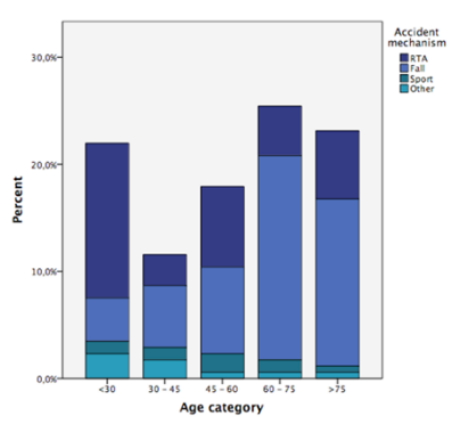

Figure 1: Accident mechanisms subdivided according to age groups: In the different age categories subgroups. Percentages are relative to the overall population. Accident mechanism: RTA: Road traffic accidents, fall, sport and other

\section{Injury severity}

All injuries to the head and other body regions were coded according to the AIS (Abbreviated Injury Severity Score) system $[3,5]$. $56.7 \%$ of patients had an AIS head of $4,41.0 \%$ of the patients an AIS head of 5 and $2.2 \%$ an AIS head of 6 . The rates were nearly equal among the subgroups (Table 1). $68 \%$ of all patients had concomitant injuries of at least one body region other than the head, with AIS $\geq 1$ and $33.7 \%$ with AIS $\geq 3.35 .4 \%$ of the patients had more than one concomitant injury.

The overall mean ISS was 28.5 ( \pm 13.9 ), with highest scores in the age group <30 $(36.3 \pm 13.9)$ and lowest in the "75+" group (23.3 \pm 7.4$)$. The remaining groups are shown in Table 2 . The difference in the ISS between the groups is significant in the one way ANOVA $(p=0.001)$. Post-hoc tests showed significant differences between the $<30$ subgroup and the $60-75$ and $75+$ groups $(p=0.041$ and $p=0.001$ respectively).

\section{Neurological status and neurosurgical treatment}

The over-all mean GCS at the site of accident was $10.0 \pm 4.4 .41 .3 \%$ of the patients had a GCS $\geq 13$, followed by $37.8 \%$ with GCS $\leq 8$ and $20.9 \%$ with GCS 9-12. Details are listed in Table 2. The subgroup $<30$ years had the lowest mean GCS $(8.9 \pm 4.2)$ and the subgroup $75+$ had the highest mean initial GCS $(11.5 \pm 3.7)$. Pearson's chi-square test revealed significant differences between the groups $(\mathrm{p}=0.035)$.

The overall mean GCS at day 14 was $13.8 \pm 2.6$. In all age groups, the majority of the patients had a GCS $\geq 13(84.7 \%$, details for all subgroups are presented in Table 2), with no significant differences in Pearson's chi-square test $(\mathrm{p}=0.76)$. The subgroup of the patients $30-$ 45 had the highest mean score $(14.4 \pm 1.6)$. The other groups exhibited only slight differences from the overall mean. The patients who died during the study period hat a significant lower mean GCS on scene than the survivors $(7,2 \pm 4.5$ vs. $11,1 \pm 3,9, \mathrm{p}<0.001)$.

Neurosurgical intervention was indicated in $35.4 \%$ of patients. This included decompressive craniotomy (12.4\%), hematoma evacuation (5.6\%), intraventricular drainage (10.7\%) and others (6.7\%). 64.6\% of the patients did not undergo any neurosurgical intervention. $35.2 \%$ of the patients $(\mathrm{N}=63)$ were intubated at the place of accident; $20.7 \%(\mathrm{~N}$ $=37$ ) were intubated in the emergency department. 
Citation: Kuenzler M, Braun CT, Maeder MB (2015) Mortality and Outcome of Severe Traumatic Brain Injury in a Swiss Level One Trauma

\begin{tabular}{|c|c|c|c|c|c|c|c|c|c|c|c|c|c|}
\hline \multicolumn{13}{|c|}{ Age category } & \multirow[t]{2}{*}{$p$ value } \\
\hline & \multicolumn{2}{|c|}{$\begin{array}{l}\text { All } \\
\mathrm{N}(\%)\end{array}$} & \multicolumn{2}{|c|}{$\begin{array}{l}<30 \\
N(\%)\end{array}$} & \multicolumn{2}{|c|}{$\begin{array}{l}31 \text { - } 45 \\
\mathrm{~N}(\%)\end{array}$} & \multicolumn{2}{|c|}{$\begin{array}{l}46-60 \\
N(\%)\end{array}$} & \multicolumn{2}{|c|}{$\begin{array}{l}61 \text { - } 75 \\
N(\%)\end{array}$} & \multicolumn{2}{|c|}{$\begin{array}{l}>75 \\
\mathrm{~N}(\%)\end{array}$} & \\
\hline \multicolumn{14}{|c|}{ GCS at scene } \\
\hline$\leq 8$ & 65 & $(37.8)$ & 20 & (48.8) & 7 & $(36.8)$ & 11 & $(37.9)$ & 19 & $(44.2)$ & 8 & (20) & 0.035 \\
\hline $9-12$ & 36 & $(20.9)$ & 10 & $(24.4)$ & 4 & $(21.1)$ & 1 & (3.4) & 9 & (20.9) & 12 & (30) & \\
\hline$\geq 13$ & 71 & $(41.3)$ & 1 & (26.8) & 8 & $(42.1)$ & 7 & (58.6) & 5 & (34.9) & 20 & (50) & \\
\hline \multicolumn{14}{|c|}{ GCS at day 14} \\
\hline$\leq 8$ & 9 & $(6.6)$ & 2 & (6.5) & 0 & & 3 & (11.1) & 3 & (9.1) & 1 & (3.6) & 0.76 \\
\hline $9-12$ & 12 & $(8.8)$ & 3 & $(9.7)$ & 2 & (11.1) & 1 & $(3.7)$ & 2 & (6.1) & 4 & (14.3) & \\
\hline$\geq 13$ & 16 & (84.7) & 6 & $(83.9)$ & 6 & (88.9) & 3 & (85.2) & 8 & (84.8) & 3 & (82.1) & \\
\hline \multicolumn{14}{|c|}{ AIS head } \\
\hline 4 & 01 & $(56.7)$ & 22 & (53.7) & 15 & $(71.4)$ & 9 & (61.3) & 20 & (44.4) & 25 & (62.5) & \\
\hline 5 & 3 & (41) & 17 & (41.5) & 6 & (28.6) & 1 & (35.5) & 24 & (53.3) & 15 & (37.5) & \\
\hline 6 & 4 & $(2.2)$ & 2 & $(4.8)$ & 0 & & 1 & (3.2) & 1 & (2.2) & 0 & & \\
\hline $\begin{array}{l}\text { Injury } \\
\text { Severity } \\
\text { Score }\end{array}$ & 28 & $\pm 14^{* \dagger}$ & 6 & \pm 19 & 8 & \pm 16 & 7 & \pm 13 & 7 & $\pm 9^{\dagger}$ & 3 & $\pm 7^{*}$ & 0.001 \\
\hline
\end{tabular}

Table 2: Neurological status and injury severity: $\mathrm{p}$-values indicate the differences among all groups

\section{Mortality}

During the study period, 47 patients $(26.4 \%)$ died. Of these patients, 39 (21.9\%) died within 14 days and 8 (4.5\%) after day 14 , but within one year of the accident.

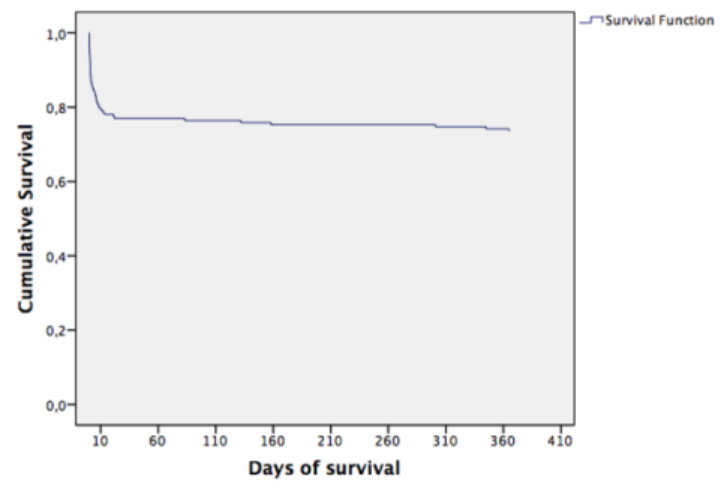

Figure 2: Kaplan-Meyer's survival curve of the study population. This illustrates high mortality within the first 8 days and flattening after this period

These 8 patients were all aged 60 years and above ( 4 in the $60-75$ and 4 in the $75+$ subgroup). All non-survivors who died within the first three days were younger than 60 years $(<30,30-45,45-60$ year subgroups). Mean survival time of all patients was $43.8 \pm 86.5$ days and the median survival time was 1.8 days. The mean survival time differed between the age groups (see Table 1): The $30-45$ year group had the lowest values $(0.25 \pm 0.6$ days) and the $75+$ group the highest $(49.6 \pm$ 109.8 days). Figure 2 shows the Kaplan-Meyer survival curve of the study population. As shown in Table 1, the subpopulation of patients of $75+$ years had the highest mortality rate, with $45 \%(\mathrm{~N}=18)$, followed by the $60-75$ year subpopulation $(33.3 \%, \mathrm{~N}=15)$. The differences in mortality between the groups are significant (Pearson's chi-square test, $\mathrm{p}=0.004$ ).

\section{Hospital treatment and rehabilitation}

The majority of the patients were directly admitted to the Emergency Department (ED) $(69.7 \%, \mathrm{~N}=124)$. As shown in Table 1, the subgroups of the patients $>60$ years were more likely to be indirectly admitted to the $\mathrm{ED}(33.3 \%$ in the $60-75$ group and $42.5 \%$ in the $75+$ group) than the younger age groups.

$81.5 \%$ of all patients were admitted to the Intensive Care Unit (ICU). The mean stay in the ICU was $4.7 \pm 7.2$ days. The mean total hospital stay was $11.6 \pm 12.7$ days, with only slight differences between the groups (Table 1).

At day 14 , only $11.8 \%(\mathrm{~N}=21)$ of the patients were still being treated at the Trauma Center; mean while $44.9 \%(\mathrm{~N}=80)$ were in external acute care hospitals, $6.2 \%(\mathrm{~N}=11)$ at home and $15.7 \%(\mathrm{~N}=$ 28 ) in a neurorehabilitation unit or hospital. Details of the subgroups are shown in Table 1. 
For 58 Patients (32.6\%), treatment of their TBI included neurological rehabilitation in a specialized rehabilitation center. The average duration of treatment was $74.9 \pm 77.1$ days. The " $75+$ " group had the shortest duration $(35.3 \pm 24.1$ days $)$.

\section{Discussion}

In the present study, we evaluated the demography and outcome after severe TBI at a single tertiary trauma center. 178 patients were included in the study during a one-year period. They were all admitted to the Emergency Department of the Trauma Center in Berne, either directly or indirectly via a regional hospital. The inclusion criteria consisted of TBI due to traumatic accidents, with an AIS head $\geq 4$ confirmed by CT scan in the first 24 hours.

The primary outcome of the present study was death of the patient within one year of the accident. Overall $26 \%$ of the patients died during this period. There were significant differences in death rate among the age groups: patients $>60$ years had significant higher rates compared to those below this age ( $38.8 \%$ vs. $15.0 \%)$, despite the lower overall injury severity, as expressed in the Injury Severity Score ISS. Previously reported mortality rates of TBI patients vary considerably, with rates from $8 \%$ to $60 \%$ in different publications [6-12]. In the patient group $<60$ years, all deaths were within 3 days of the accident. In contrast, 8 patients in the groups over 60 years died after day 14 post-injury. As a result, the mean survival time between the groups varied considerably: The lowest means were in the $30-45$ groups and the highest in the $75+$ group. In their investigation of lethal injuries (not only TBI) at a Level I trauma center, Acosta et al. reported that $70 \%$ of their patients died within $24 \mathrm{~h}$ and $88 \%$ were dead within one week [13]. Gerber et al. reported a case fatality of $13 \%$ within two weeks of the accident in patients with TBI and GCS $<9$ [14].

It can be assumed that in younger patients the high mortality within the first days after injury is a direct consequence of the severe TBI or the severe accompanying injuries in these multiple trauma patients. But if they survive the first two weeks, these people have a favorable outcome. In patients older than 60 years, concomitant health problems might influence the higher mortality within one year and therefore the TBI might just be one factor for mortality. As our numbers of the oneyear follow-up are small, further research is necessary for this subgroup.

A secondary aim of the study was to describe the patient's status at two weeks post-injury. The mean GCS of the survivors at day 14 was 13.8 , with minimal variance among the age groups, and only a minority (cumulative $15 \%$ of all patients) had a GCS $<13$. Total mean length of stay in a hospital was 11.6 days, with minimal differences between the groups, which is equal to the period reported by Sugerman et al. [15]. The most frequent place of treatment at day 14 was an external hospital (to which the patients were transferred after initial treatment and stabilization at the trauma center), followed by neurorehabilitation units or hospitals and the trauma center itself. To the best of our knowledge, the place of treatment at day 14 after the accident has not been described in previous studies. Neurorehabilitation was effected in $32 \%$ of the patients, which is of the same order as described by Masson and Sugerman et al. [15,16].

The present article is a prospective cohort study in one of the largest trauma centers in Switzerland.

Based on the fact that we concentrated on one trauma center, we could minimize possible effects of different approaches to patients with severe TBI in the emergency and the intensive care. Moreover we were able to minimize inter-rater reliability because only one person decided on the inclusion of the patients, and follow-up of the patient within our hospital was easy to obtain.

\section{Limitations}

Our study has both strengths and limitations. Firstly, it is a prospective report of a patient cohort treated in a tertiary trauma center, with extensive data collected during a one year period. The inclusion to the study was performed by only a single investigator, thus eliminating inter-rater variability. Limitations include the small sample size and the loss of patients - mainly for the one-year followup. Moreover, only the patients treated at a tertiary center could be analyzed. This may bias our sample, as older patients with TBI but a rather good initial neurological condition is less likely to be transferred to a trauma center [17].

\section{Conclusion}

The characteristics and the outcome of the patients with severe TBI at the Trauma Center of the University Hospital in Berne do not differ from other hospitals in industrialized countries. Young patients with a severe TBI, often caused by road traffic accidents, usually have a higher overall ISS and die within the first days post-injury. If they survive, they have a favorable outcome.

Falls were the most frequent accident mechanism in elderly patients. Although they caused less severe injuries than RTA or other accidents, they were associated with higher but late mortality in this population. Further efforts are needed for the prevention of these accidents, and the treatment of the patients requires special awareness by emergency medical services and treating doctors.

\section{Acknowledgements}

We thank the involved persons and their families for their contribution and participation. We thank Rodney Yeates for English language editing and Meret Ricklin for revision of the manuscript.

\section{References}

1. Walder B, Haller G, Rebetez MM, Delhumeau C, Bottequin E, et al. (2013) Severe traumatic brain injury in a high-income country: an epidemiological study. J Neurotrauma 30: 1934-1942.

2. Thomas A, Gennarelli EW (2008) The Abbreviated Injury Scale 2005. ed2008: American Association for Automotive Medicine (AAAM).

3. Garthe E, States JD, Mango NK (1999) Abbreviated injury scale unification: the case for a unified injury system for global use. J Trauma 47: 309-323.

4. Dick WF, Baskett PJ, Grande C, Delooz H, Kloeck W, et al. (2000) Recommendations for uniform reporting of data following major trauma--the Utstein style. An International Trauma Anaesthesia and Critical Care Society (ITACCS) initiative. Br J Anaesth 84: 818-9.

5. Copes WS, Champion HR, Sacco WJ, Lawnick MM, Keast SL, et al. (1988) The Injury Severity Score revisited. J Trauma 28: 69-77.

6. Huang YH, Lee TC, Lee TH, Liao CC, Sheehan J, et al. (2013) Thirty-day mortality in traumatically brain-injured patients undergoing decompressive craniectomy. J Neurosurg 118: 1329-1335.

7. Leijdesdorff HA, van Dijck JT, Krijnen P, Vleggeert-Lankamp CL, Schipper IB; Regional Trauma Center West-Netherlandsâ $€^{\text {Tx }}$ Research Group (2014) Injury pattern, hospital triage, and mortality of 1250 patients with severe traumatic brain injury caused by road traffic accidents. J Neurotrauma 31: 459-465. 
Citation: Kuenzler M, Braun CT, Maeder MB (2015) Mortality and Outcome of Severe Traumatic Brain Injury in a Swiss Level One Trauma Center. Emerg Med (Los Angel) 5: 226. doi:10.4172/2165-7548.1000226

Page 6 of 6

8. Martins ET, Linhares MN, Sousa DS, Schroeder HK, Meinerz J, et al (2009) Mortality in severe traumatic brain injury: a multivariated analysis of 748 Brazilian patients from Florianópolis City. J Trauma 67: 85-90.

9. McIntyre A, Mehta S, Aubut J, Dijkers M, Teasell RW (2013) Mortality among older adults after a traumatic brain injury: a meta-analysis. Brain Inj 27: 31-40.

10. Härtl R, Gerber LM, Iacono L, Ni Q, Lyons K, et al. (2006) Direct transport within an organized state trauma system reduces mortality in patients with severe traumatic brain injury. J Trauma 60: 1250-1256.

11. Andelic N, Anke A, Skandsen T, Sigurdardottir S, Sandhaug M, et al (2012) Incidence of hospital-admitted severe traumatic brain injury and in-hospital fatality in Norway: a national cohort study. Neuroepidemiology 38: 259-267.

12. Patel HC, Bouamra O, Woodford M, King AT, Yates DW, et al. (2005) Trends in head injury outcome from 1989 to 2003 and the effect of neurosurgical care: an observational study. Lancet 366: 1538-1544.
13. Acosta JA, Yang JC, Winchell RJ, Simons RK, Fortlage DA, et al. (1998) Lethal injuries and time to death in a level I trauma center. J Am Coll Surg 186: 528-533.

14. Gerber LM, Chiu YL, Carney N, Härtl R, Ghajar J (2013) Marked reduction in mortality in patients with severe traumatic brain injury. J Neurosurg 119: 1583-1590.

15. Sugerman DE, Xu L, Pearson WS, Faul M (2012) Patients with severe traumatic brain injury transferred to a Level I or II trauma center: United States, 2007 to 2009. J Trauma Acute Care Surg 73: 1491-1499.

16. Masson F, Thicoipe M, Aye P, Mokni T, Senjean P, et al. (2001) Epidemiology of severe brain injuries: a prospective population-based study. J Trauma 51: 481-489.

17. Chang DC, Bass RR, Cornwell EE, Mackenzie EJ (2008) Undertriage of elderly trauma patients to state-designated trauma centers. Arch Surg 143: 776-781. 